Mechanical Engineering: An International Journal (MEIJ), Vol. 5, No.1/2, May 2018

\title{
DESIGN AND 3D PRINT OF AN EXPLORER ROBOT
}

\author{
Rodrigo Uzziel Gutiérrez Castillo and José Reyes Rosales \\ Department of Mechatronic Engineering, Higher Technological Institute of Atlixco, \\ Atlixco, Puebla, Mexico
}

\begin{abstract}
This paper describes the design and $3 d$ print of an explorer robot with suspension rocker-bogie which is based in the robots sent into space. Also, it describes of software to acquire the image in real time and the control of robot. It should be noted that space exploration has been a feature of governments for many years. Nowadays there are companies that can transport loads to space; There are also companies that have made great advances in robotics and manufacturing. These technological advances can help in space exploration, either by making robots lighter and easier to manufacture or even by creating pieces and tools from space.
\end{abstract}

KEYWORDS

3D Printer, 3D Print, Additive manufacturing, FDM, Mechanic design, Mobile robot, Rocker-Bogie, Rover, Video Streaming \& Wireless control.

\section{INTRODUCTION}

The explorer robots are mechanisms which have a locomotion system, cameras to take pictures and to transmit video live streaming and sensors that can help the research work.

NASA has used this type of robots for space exploration. The last one send to Mars was in the year 2011 whose mission is to investigate if there was or is life on that planet. [1]. Mexico is not far behind as in the second half of 2019 the Mexican Space Agency (AEM) plans to send 8 robots that together will create a solar panel for future space exploration [2].

However, the applications of robots with locomotion and video transmission in real time do not remain only in space. A clear example is Ixnamiki Olinki (people search engine) which is a rescue and assistance robot in natural disasters [3]. In short, mobile robotics has a wide range of applications.

The present work exposes the creation of an explorer robot which can be applied in diverse situations as in the space exploration (only the design, the material used not), assistance in natural disasters and even with didactic aims.

The object of this project is to create a rover robot of low cost which can be used in different situations.

The rover has system Rocker-Bogie, 6 wheels and engines, more of 20 pieces; it is designed and manufactured in 3D print, for its control it is used a raspberry pi devices and camera, the bridge $\mathrm{H}$ is used for motors driver. It will control via wifi by Computer. The most important findings are:

- Cheaper production

- Fast and accurate manufacturing

- Faster engineering changes

DOI: $10.5121 /$ meij.2018.5201 
- 3D print material a bit complicated. This material is only compatible with the terrestrial environment, but there is still no evidence to implement it in the cosmos.

- Efficient robot control

It is a robot which if a piece should was damaged it wouldn't need a long waiting time to be able to acquire it since it can be manufactured in a few hours.

\section{DEVELOPER OF CONTENT}

This robot is developer on based to:

- Design CAD/CAM

- Additive manufacturing/3D print

- Electromechanical system

- Algorithms to control the movements of robot

- Communication PC-Raspberry

- Live video streaming

\subsection{DESIGN CAD/CAM}

A CAD design is a 3D model of some part which will be manufactured. The CAM software is the one that is dedicated to manipulate the modeled pieces and then be machined or printed in 3D [4].

The design of the robot consists of using the Rocker-Bogie suspension to navigate difficultto-access environments. The robot has six wheels. One axis of rotation goes between two tires called Bogie and the other is between the rear tire and the body of the robot called Rocker. It has been widely used in NASA rovers [1]. To have a better overview of what has been described, it can be seen that in Fig. 1 the kinematic diagram of the Rocker-Bogie mechanism is shown [5].

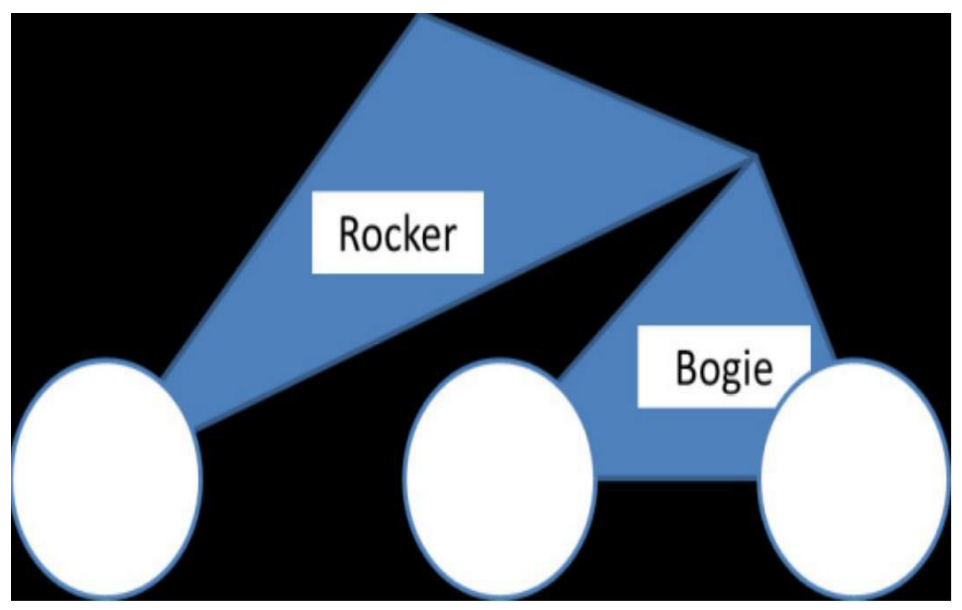

Fig. 1 Rocker-Bogie mechanism Kinematic diagram 
In Fig. 2 the design of a robot with the aforementioned mechanism which is known as Lightweight Survivable Rover (LSR-1) which means Rover of light survivor. This model is representative of NASA as a prototype of a planetary rover [6].

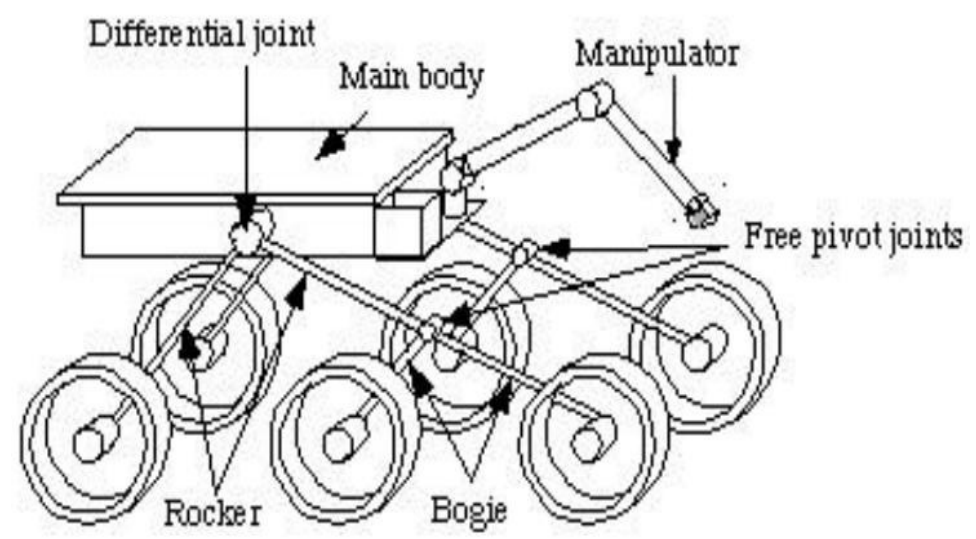

Fig. 2 Rocker-Bogie robot diagram (LRS-1).

The CAD design of robot with Rocker-Bogie suspension designed in this work is shown in Fig. 3 in which the electronic components it has are also observed. Raspberry Pi 3 card (green object), H-bridges (cream objects next to green object), motors coupled to the wheels, camera (Forward of green and cream component) and battery (under green and cream component).

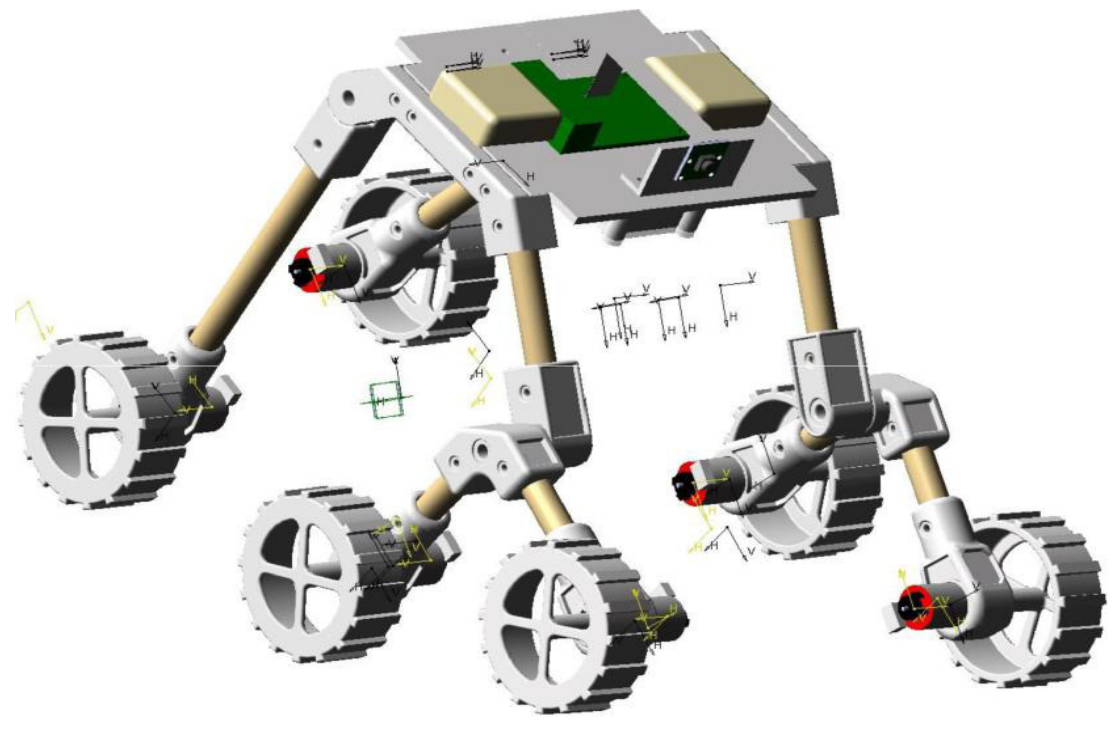

Fig. 3 CAD design of the robot with its electronic components.

The dimensions of the system are important to have good a mechanical stability. These dimensions are shown in Fig. 4. It should be mentioned that the dimensions of the mechanism are not those of the robot and also the Rocker has a shift to the left. The robot has a height of $286.5 \mathrm{~mm}$ taking into account from the base of the rims to the support of the camera and the rims to the base of the body $251.2 \mathrm{~mm}$, width $350 \mathrm{~mm}$ left rims to right of the Bogie and $577.6 \mathrm{~mm}$ long front to rear tire. All the dimensions are in accordance with Fig. 4 since when entering a broken ground they are modified. 
The lateral parts of the Bogie measure $121.7 \mathrm{~mm}$ which form an angle of $90^{\circ}$. The Rocker measures twice as much as the Bogie (243.4) forming a $90^{\circ}$ angle with the Bogie and offsetting $137.4 \mathrm{~mm}$ to the left. The dotted circles represent the axes of rotation.

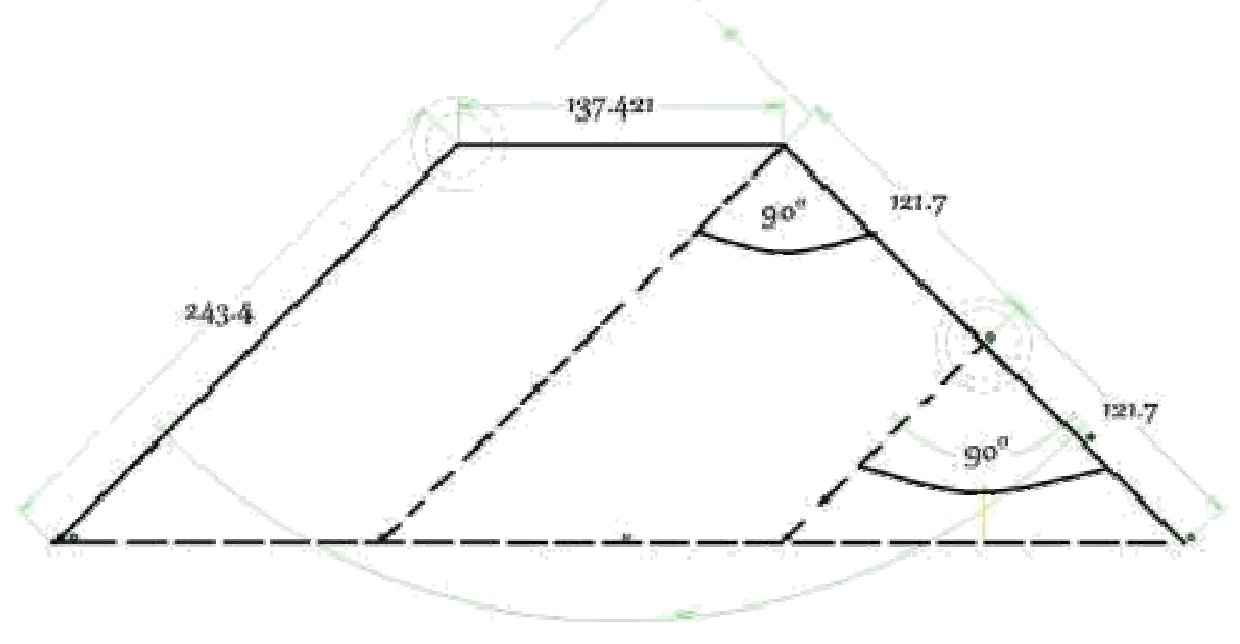

Fig. 4 Dimensions of the Rocker-Bogie mechanism.

The mechanism implemented in the robot as we already know is used to navigate in broken terrain and also to climb some obstacles. The maximum you can climb at a $90{ }^{\circ}$ angle is between 1.5 to 2 times the diameters of the rims [7] which would be between $144 \mathrm{~mm}$ to $192 \mathrm{~mm}$ maximum since each rim measures $96 \mathrm{~mm}$ in diameter, in Fig. 5 it is shown the movement of the rim when climbing $90^{\circ}$ obstacles such as a step.

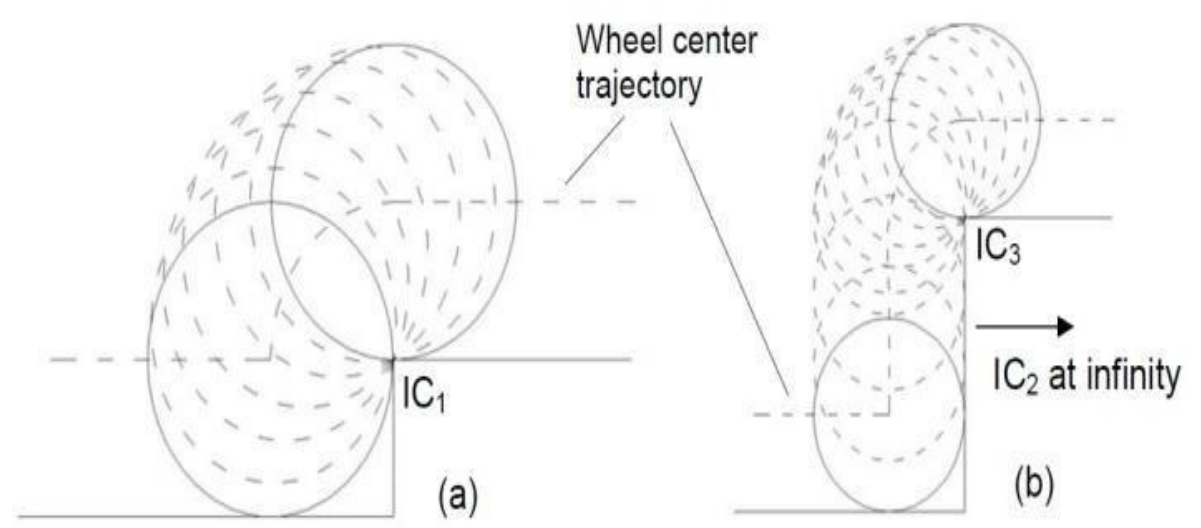

Fig. 5 Rims passing over its diameter (a) and more than its diameter (b).

We can also know at what speed to manipulate the robot. We know that its function is to explore on irregular terrain and not that one a race car. Having a Rocker-Bogie suspension makes it easier for us to navigate through rigorous environments, but we cannot go at high speeds. Table 1 describes the speed at which one must go with respect to the diameter of the tires [8]. The speed at which the robot has to go is at $10 \mathrm{~cm} / \mathrm{s}$. 
Mechanical Engineering: An International Journal (MEIJ), Vol. 5, No.1/2, May 2018

Table 1 Robot speed in $\mathrm{cm} / \mathrm{s}$ to which you must take into account the diameter of the tires in $\mathrm{cm}$ and the speed of the engines in rpm.

\begin{tabular}{|c|c|c|}
\hline \multirow{3}{*}{ Velocity $10 \mathbf{c m} / \mathbf{s}$} \\
\hline \multirow{2}{*}{ RPM } & \multicolumn{2}{|c|}{ Diameter } \\
\cline { 2 - 3 } & M & Cm \\
\hline 10 & 0.191 & 19.096 \\
\hline 20 & 0.095 & 9.548 \\
\hline 30 & 0.064 & 6.365 \\
\hline 40 & 0.048 & 4.774 \\
\hline 50 & 0.038 & 3.819 \\
\hline 60 & 0.032 & 3.183 \\
\hline 70 & 0.027 & 2.728 \\
\hline 80 & 0.024 & 2.387 \\
\hline 90 & 0.021 & 2.122 \\
\hline 100 & 0.019 & 1.91 \\
\hline & & \\
\hline
\end{tabular}

\subsection{Additive ManufaCturing/3D Printing}

The choice of additive manufacturing or 3D printing is due to its great versatility. With it, we can create structures in less time and more economically, which allows the creation of cutting-edge technological components.

There are various types of additive manufacturing of which there is a wide variety of materials such as photoresins, metal powders, plastics and even chocolate.

On this occasion, the method that allows the use of plastic called FDM (Modeled by molten deposition) was used. In the there are various materials such as the PLA, ASA, ABS and PETG by citing some examples. The material used is PETG (polyethylene terephthalate) for its properties which are:

- Rigidity

- Resistance to impacts and efforts

- Resistance to temperature, at $80^{\circ} \mathrm{C}$ it starts to deform

- Chemical resistance

- Recyclable

Despite having good characteristics, this material has not been tested in the cosmos.

As the robot designed is for exploration, it has to have good exterior properties, resistance to changes in temperature and impacts. For this reason the chosen material is PETG. Figure 6 shows the final assembly of the explorer robot with all its mechanical and electronic components. 


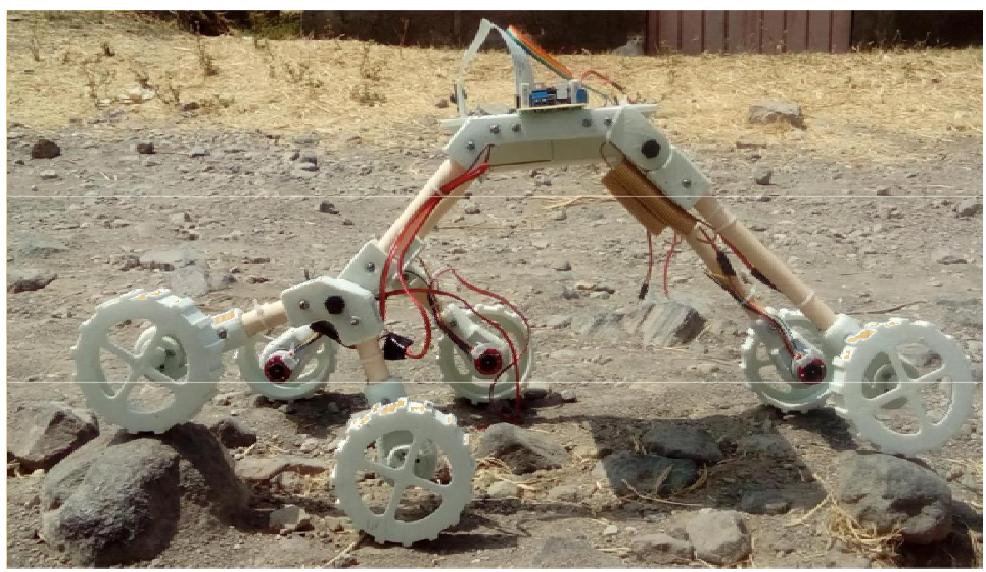

Fig. 6 Robot assembled with pieces printed in 3D FDM and PETG material. The Rocker has a spring so that the leg of the robot does not rotate too much and can return to its original position

\subsection{ELECTROMECHANICAL SySTEM}

So that the robot with the Rocker-Bogie mechanism can be maneuvered from a remote point and at the same time have a visualization of the area where it is located, it is necessary to implement electronic components with which it will be possible to have higher security in terms of control over the motors.

\subsubsection{RASPBerry Pi 3 MODEL B.}

It is a card in which is an embedded computer where the program to control the engines, transmission / reception of commands and video in real time is located. This board is programmed with Python language, also has its own operating system. Its most outstanding features are:

- CPU: Quad-Core Cortex A7 to 900MHZ

- GPU: Video Core IV of two cores

- RAM: 1GB DDR2

- Ports:

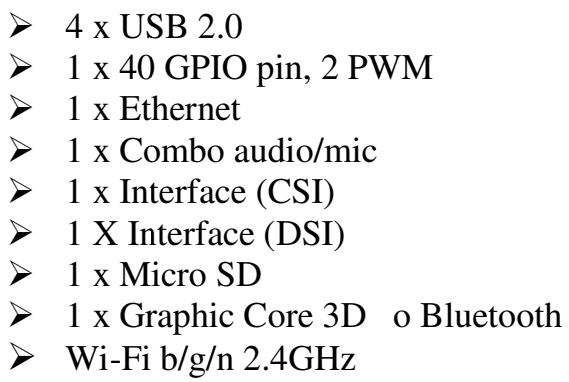

The most important feature of Raspberry is its memory which is 1GB sufficient to control the robot, also because it is very light and small. Another important feature is that the Raspberry is compatible with the camera doing that the live video streaming be fast and easy. 


\subsubsection{CAMERA.}

This device helps us verify that the advance of the robot is safe. Without it practically the robot that was created could not be occupied to explore. Its peculiarities are:

- $5 \mathrm{Mpx}$

- Resolution $2592 * 1944$

- Video 1080 p 30fps, 720 p 60fps, $640 * 480$ p

- Size: $25 \mathrm{~mm} * 24 \mathrm{~mm} * 9 \mathrm{~mm}$

\subsubsection{BATTERY.}

It is the power supply which will supply power to the Raspberry, H Bridge and motors. Its general properties are:

- Voltage $11.1 \mathrm{v}$

- 2.2Ah current

- $30 \mathrm{c}$

\subsubsection{BRIDGe H / PoWer Stage.}

With this electronic component we can control the direction of rotation of the motors and in this way exert control over the motor in such a way that it can go forward or backward and make turns to the left or right. At the same time it has power stage whose purpose is to exert greater amperage to be able to move the motors. Their characteristics are:

- Maximum power voltage 36v

- Maximum DC current 4A

- $3.3 \mathrm{v}-5 \mathrm{v}$ logic input

\subsubsection{ENGINES.}

The robot has 6 wheels due to the suspension mechanism used the robot has 6 engines. The properties of the engines are:

- Shaft diameter: $4 \mathrm{~mm}$, type ' $\mathrm{D}$ '

- Encoder power supply voltage: $5 \mathrm{v}$

- Encoder connector: 6 signals

- Motor supply voltage: DC $6 \mathrm{v}$ to $12 \mathrm{v}$

- Speed without load: 210RPM, $0.13^{\mathrm{a}}$

- Torque with nominal load: $2.0 \mathrm{~kg} . \mathrm{cm} / 170 \mathrm{rpm} / 2.0 \mathrm{~W} / 0.60^{\mathrm{a}}$

- Torque with maximum load: $5.2 \mathrm{~kg} . \mathrm{cm} / 110 \mathrm{rpm} / 3.1 \mathrm{~W} / 1.10^{\mathrm{a}}$

- Relationship in gears: 1:34

All the components described are shown in Fig. 3.

\subsection{COMMUNICATION PC-RASPBERRY}

To manipulate a robot remotely it is necessary to carry out a wireless communication. The steps that are required to achieve this feat are:

- Create a file to configure the internet network. This way, when you turn the Raspberry on automatically, it will enter the WIFI network.

- Next to the card is connected a monitor, keyboard and mouse to be able to install the SSH communication protocol by command in the terminal. 
- We can now remove the items attached to the card. From the computer using the Putty software, we enter the Raspberry with its IP SHH 22. The terminal will appear in which we will install VNC by means of commands and we will configure the card.

- Finally we use VNC Viewer to enter the Raspberry.

Once we perform the previous steps we can make a remote connection. In this way we can control the explorer robot and obtain real-time video of its movements and environment.

\subsection{Algorithms To Control The Movements Of Robot}

Algorithms are the basis of programming. By having a PC-Raspberry connection you can send commands or even software to control the motors and in this way the movements of the robot. The algorithms necessary to move the robot are:

1. Stop. Consists in:

- P1. De-energize the motors of the two sections.

2. Turn. It consists of giving direction to the robot, either right or left. To achieve this, it is necessary to take into account the following steps:

- G1. Turn off the motors of the two sections (P1).

- G2. If it is a left turn, energize section 2 of the robot positively and section 1 negatively.

- G3. If it is a right turn, energize section 1 of the robot positively and section 2 negatively.

- G4. Turn off the motors of the two sections (P1).

3. Advances. Determines whether the robot is going forward or going backwards. It consists of following the following guidelines:

- A1. If you are unemployed and you need to go forward, feed the two sections in a positive way.

- A2. If you are unemployed and you need to go backwards, energize the two

- sections negatively.

- A3. If you are moving forward and you need to go back, first perform a P1 and then feed the two sections negatively (A2).

- A4. If you are going backwards and you need to go forward, first make a P1 and then energize the two sections positively (A1).

These algorithms are applied to a true table to be able to control the motors by digital pulses $(0,1)$. Table 2 describes the pulses that have to be sent to control the movements of the robot taking into account the following:

4. $S_{1 \mathrm{~N}}$ : Section 1 of the robot fed negatively.

5. $S_{2 \mathrm{~N}}$ : Section 2 of the robot energized negatively.

6. $S_{1 \mathrm{P}}$ : Section 1 of the robot fed positively.

7. $\mathrm{S}_{2 \mathrm{p}}$ : Section 2 of the robot energized positively.

8. M: Robot movement. 
The sections 1 and 2 are representative in Fig. 7.

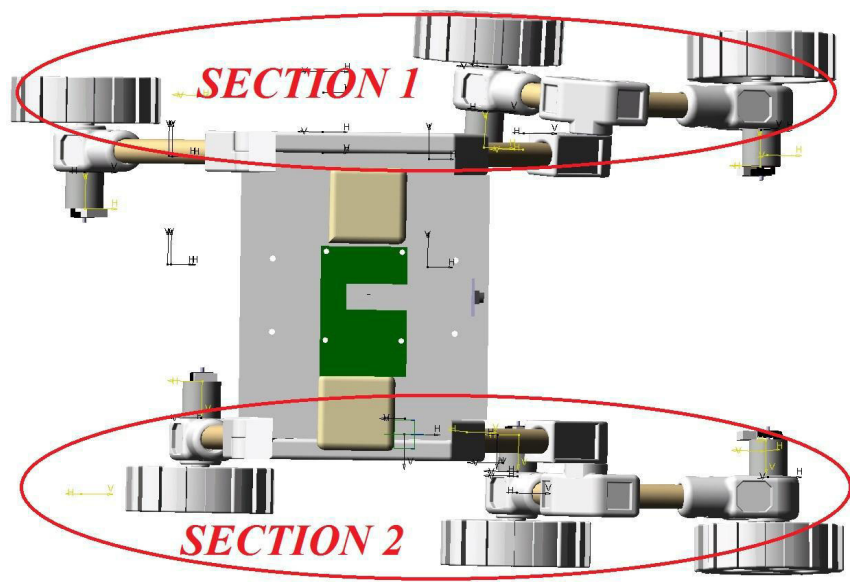

Fig. 7 Section 1 and section 2 of the robot.

Table 2 True table of the algorithm to control the robot movements of the OR type.

\begin{tabular}{|c|c|c|c|c|c|}
\hline S1N & S1P & S2N & S2P & $\mathbf{M}$ & \\
\hline 0 & 0 & 0 & 0 & 0 & P1 \\
\hline 0 & 0 & 0 & 1 & 1 & \\
\hline 0 & 0 & 1 & 0 & 1 & \\
\hline 0 & 0 & 1 & 1 & 1 & \\
\hline 0 & 1 & 0 & 0 & 1 & \\
\hline 0 & 1 & 0 & 1 & 1 & A1 \\
\hline$\overline{0}$ & 1 & 1 & $\overline{0}$ & 1 & G3 \\
\hline 0 & 1 & 1 & 1 & 1 & \\
\hline 1 & 0 & 0 & 0 & 1 & \\
\hline 1 & $\mathbf{0}$ & 0 & 1 & 1 & G2 \\
\hline 1 & $\mathbf{0}$ & 1 & $\mathbf{0}$ & 1 & A2 \\
\hline 1 & 0 & 1 & 1 & 1 & \\
\hline 1 & 1 & 0 & 0 & 1 & \\
\hline 1 & 1 & 0 & 1 & 1 & \\
\hline 1 & 1 & 1 & 0 & 1 & \\
\hline 1 & 1 & 1 & 1 & 1 & \\
\hline
\end{tabular}

The implementation of the control is through the keyboard of the computer, the numbers 8,4 , $6,2,5$ generate the movement of the robot giving the signals that are showed in table 2. Each number represents a control algorithm, which are associated with:

- 8 with algorithm A1.

- 2 with algorithm A2.

- 6 with algorithm $\mathrm{G} 3$.

- 4 with algorithm G2.

- 5 with algorithm P1.

According to Table 1, where the RPM of a Rocker-Bogie robot equals 20 with a diameter of $9.5 \mathrm{~cm}$ on the wheels and we know that the engine speed is $210 \mathrm{RPM}$ without load, 170rpm 
with a nominal load of $2 \mathrm{Kg} / \mathrm{cm}$ and $110 \mathrm{RPM}$ with a nominal load value of $5 \mathrm{Kg} / \mathrm{cm}$, we have the following table that shows the percentage of PWM that is applied to the engines with respect to the characteristics contributed. In this way, we have control of the speed of the motors with respect to the nominal weight of the robot.

Table 3 PWM applied with respect to engine speed to obtain a speed of 20 RPM for the robot.

\begin{tabular}{|c|c|c|}
\hline $\begin{array}{c}\text { RPM Motor } \\
(\mathbf{1 0 0 \%} \\
\text { PWM) }\end{array}$ & $\begin{array}{c}\text { Nominal } \\
\text { load } \\
(\mathbf{K g} / \mathbf{c m})\end{array}$ & $\begin{array}{l}\text { \% PWM } \\
\text { to have } \\
\text { 20RPM }\end{array}$ \\
\hline 210 & 0 & 9.52 \\
\hline 170 & 2 & 11.76 \\
\hline 110 & 5 & 18.18 \\
\hline
\end{tabular}

Control of the system can be better using an analog circuit to generate the cosine function mapping because "The main advantage with the analog solution for trigonometric functions is a continuous time response at high frequency and with no quantization error" [9]

\subsection{LIVE VIDEO STREAMING}

To make video transmission we will use pre-established algorithms which are free and easy to implement. These algorithms can be downloaded in [10]. These algorithms belong to artificial vision libraries known as OpenCV. Below is the code to use the camera.

import numpy as $n p$

import cv2

cap $=$ cv2.VideoCapture $(0)$

while(True):

\# Capture frame-by-frame ret, frame = cap.read ()

\# Our operations on the frame come here

gray $=$ cv2.cvtColor(frame, cv2.COLOR_BGR2GRAY)

\# Display the resulting frame

cv2.imshow('frame',gray)

if cv2.waitKey(1) \& $0 x F F==\operatorname{ord}(' \mathrm{q}$ '):

break

\# When everything done, release the capture

cap.release()

cv2.destroyAllWindows()

\section{Conclusions}

It is a robot which if a piece should be damaged does not need a long waiting time to be able to acquire it since it can be manufactured in a few hours.

The Rocker-Bogie mechanism can be used in different situations, the most applied is in space exploration. However, its applications can be larger, such as the educational use in which students can redesign the parts of this robot and print them in 3D or even create software for autonomous control. 
Another use of the robot can be of help in disaster areas, having an integrated camera that can observe the areas in which it navigates. Maybe one day they will create materials to be manufactured with 3D printing that are capable of supporting the cosmos so that this robot can be sent to the moon or even to Mars.

The robot having electronic, mechanical and control system is said to be a Mechatronic system that "Once the product is in operation, an estimate of reliability is carried out based on the return of experience "REX" data. It is applied during the first steps and helps correct defects in design and manufacturing/production". [11]

\section{ACKNOWLEDGEMENTS}

The authors of this document are grateful for the opportunity to disseminate the work done of the explorer robot manufactured in 3D printing. We thank all the authors of various articles that were of great help for the design of the robot.

\section{REFERENCES}

[1] mars.nasa.gov/msl/mission/rover/

[2] u-gob.com/8-robots-mexicanos-a-la-luna-en-2019/

[3] hipertextual.com/2017/09/robot-que-ayuda-salvar-victimas-terremoto-mexico

[4] www.autodesk.mx/solutions/cad-cam

[5] S.F. Toha, Z Zainol (2015), "System Modelling of Rocker-Bogie Mechanism for Disaster Relief", Department of Mechatronics, International Islamic University Malaysia, Kuala Lumpur, Malaysia, Rep. Tec. 76243 - 249, 2015.

[6] H. Hacot, S. Dubowsky, P. Bidaud (1998), Analysis and simulation of a Rocker-Bogie exploration rover, Department of Mechanical Engineering, Massachusetts Institute of Technology Cambridge, Laboratoires de Robotique de Paris - Centre Universiatire de Technologie,

[7] F. Barlas (2004), Design of a Mars Rover Suspension Mechanism, MS Thesis, Izmir Institute of Technology.

[8] A. Kumar, N. Verma, D. Garg, R. Hans (2015), "Design \& Fabrication of Rocker-Bogie Mechanism”, Department of Mechanical Engineering , D.C.R. University of Science \& Technology Murthal, Sonepat, Haryana (India), Tech. Rep. 131039.

[9] J. Reyes-Rosales, V. R. González-Díaz, J.F. Guerrero-Castellanos (2015), "New Approximation for Cosine Wave Mapping Function to Transistor Level Circuit", Benemérita Universidad Autónoma de Puebla, Puebla, Puebla, Mexico. INSPEC Accession Number: 15058576

[10] https://docs.opencv.org/3.0-beta/doc/py_tutorials/py_gui/py_video_display/py_video_display.html

[11] N. Bensaid Amrani, L. Saintis, D. Sarsri, and M. Barreau (2016), "EVALUATING THE PREDICTED RELIABILITY OF MECHATRONIC SYSTEMS: STATE OF THE ART” Mechanical Engineering: An International Journal (MEIJ).

\section{AUTHORS}

Rodrigo Uzziel Gutiérrez Castillo.Received his Bachelors Degree in Mechatronic Engineering from Higher Technological Institute of Atlixco (ITSA), Mexico in 2016; currently is working as an entrepreneur and he is working on his thesis. His research interest in the areas are Mechanic Design, 3D Print, robotic and automation.

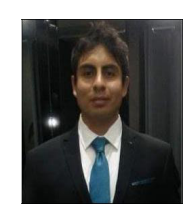

José Reyes Rosales. Received his Bachelors Degree in Mechatronic Engineering from Higher Technological Institute of Atlixco (ITSA), Mexico in 2011, and a Master of Sciences in Instrumentation from Benemérita Autonomous University of Puebla (BUAP), Mexico in 2014. Currently is working as an assistant professor at Higher Technological Institute of Atlixco (ITSA), México. His research interest in the areas are IC Design, digital

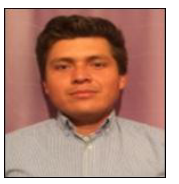
systems, control systems applications and automation. 